\title{
THE PLACE OF THE REGIONAL HOSPITAL IN POSTGRADUATE EDUCATION: A PRACTICAL APPROACH
}

\author{
ArNold Bloom, M.D., M.R.C.P. \\ Physician, The Whittington Hospital, London, N.19
}

SOME three or four thousand doctors from overseas are working in this country at the present time and it is no secret that many provincial hospitals could not function at all without their help. Many of these Commonwealth doctors come here not primarily to look for work, but to look for training. It would appear that often we fail them on both counts, since the posts we offer them may not be suitable for training purposes, and sometimes the standard of the postgraduates' training makes them unsuitable for the posts they are asked to fill. Hence there is a growing need for some enlargement of our present scheme of postgraduate education, making use of existing opportunities, however inadequate they may appear.

At the moment, facilities for postgraduate education fall far short of actual needs. The recognized postgraduate medical schools are oversubscribed and tend to provide training in the newer techniques and advanced medicine suitable for postgraduates already well versed in general principles. Similarly, other postgraduate institutions provide specialist training in such diseases as those of the heart or of the chest and are intended for graduates already advanced in general medicine. However, many of the postgraduates who come to this country do not need specialist training as much as they require general instruction in present-day medicine or surgery as it is practised in this country. These postgraduates must have the opportunity themselves to examine patients under the critical eye of their teachers. Instruction is needed on the basis of a proper and sympathetic approach to the patient, good history taking and a sound clinical examination, an evaluation of the findings and a practical approach to management and therapeutics. These techniques are best taught in regional hospitals-in fact, where else can they be taught? The undergraduate teaching hospitals are already overburdened and are being urged to open their doors to more medical students. The regional hospitals could be well suited to undertake postgraduate training, since it is these hospitals that deal with the everyday type of medical an surgical cases, and ultimately it is in regionat? hospitals that most of the postgraduates will seets employment. Two major difficulties have to be faced before regular postgraduate instruction carf be undertaken in regional hospitals; first, the availability of sufficient senior staff with time to teach and, second, the lack of physical facilities.

The consultant at a regional hospital has many commitments. $\mathrm{He}$ may be in charge of more acute beds than he can reasonably manage; it is not unknown for 80 acute beds to be under the charge of a single consultant. He will have out-patient sessions, perhaps two or three each week. He may do domiciliary visits at the reques of local doctors. Domiciliary visits are valued bl $\overrightarrow{\mathrm{t}}$ the practitioners and by the patients; they of n serve as a meeting place for hospital and family doctor, but nobody can deny that they consumes a great deal of time and energy. Most regionas hospitals have active medical committees anof these beget sub-committees, so that the consultant may have to devote a good deal of time to com $\overrightarrow{0}$ mittee work. Nor is it only hospital committees he may find himself on the management com mittee or one of the regional board committees:If he is part-time, he may attend more than ons hospital, with consequent loss of time in travelling and he may undertake sessions in private work as well. Many consultants are already involved in postgraduate teaching to local general prac titioners; they attend scientific meetings and they may undertake various research projects. Henco it must be realized at the outset that mose physicians and surgeons at regional hospitals ares already finding their time very fully occupied. In this respect, implementation of the Platt report may be of great service, since the system of senior and junior consultant working togethere should do much to relieve present stresses. The prime requisite for teaching postgraduate students at a regional hospital must be an adequate number of senior staff able and keen to undertake thesed duties. Then the burden does not fall too heavily 
on one man. As a corollary to this, there should be an adequate junior staff to take part in the teaching as well.

Let us consider the needs to be met by a regional hospital prepared to undertake postgraduate instruction of Commonwealth doctors. A class of 12 to 16 postgraduates is of manageable size, and the aim could be to provide whole-time instruction for three months. Three such courses could be held annually, with a gap in the summer, so that the hospital could be responsible for the training of about 40 postgraduates each year. For such courses in medicine a minimum of five physicians would be necessary, but eight or nine would be better. Most hospitals with a staff large enough to undertake this form of teaching will probably contain some 800 beds, and may well include special departments which will take part in the general routine: pædiatric, geriatric, and chest units for example. Under these circumstances, it is not difficult to plan a programme of bedside instruction each morning and afternoon, since each physician and his registrar can be responsible for a teaching session in his wards each week. The method of instruction will vary, but a satisfactory system is to divide the class into groups of four and for each group to examine a patient over the space of 40 minutes. The class is then reconstituted, and each of the patients examined is discussed at the bedside. The history is heard, physical signs confirmed and the management debated. This bedside instruction is the keystone of the teaching. Postgraduates are encouraged to keep notes of the cases they see so that in three months they will have had considerable practical and documented experience in the diagnosis and therapy of diseases commonly seen in hospital wards. With an adequate number of physicians and registrars taking part, undue strain does not fall on any individual. With ward teaching occupying most mornings and afternoons, the midday break before lunch offers excellent scope for formal lectures, for postmortem demonstrations, for pathology classes and for X-ray sessions. Two lectures, one pathology class and one $\mathrm{X}$-ray session each week should be sufficient to embrace subjects not covered adequately by bedside instruction. Most large regional hospitals already hold weekly staff rounds, and the postgraduates will find attendance at these rounds both valuable and stimulating. Here they will see patients they have themselves examined, and hear both the presentation and the subsequent discussion by the senior staff. The staff rounds, with an assured audience, also offer opportunities for the introduction of outside lecturers, who can enrich and enliven the material presented or can give formal lectures.

When we come to look at the physical facilities necessary to undertake this programme, we are faced with the fact that many regional hospitals are over 80 years old and, although it is tempting to indulge in plans and pleasantries for building new hospitals, the majority are unlikely to be built for at least a decade. For many years we will continue to drain time and treasure on repairing such basic deficiencies as ancient boilers and dry rot in the timber, so that any programme for postgraduate teaching may well be on a ' make do and mend' scale. Nevertheless, as will be seen, there are signs of better days and, although the hospitals bequeathed to us by our Victorian predecessors are gloomy and inefficient by modern standards, at least many of them are large and astonishingly adaptable. Often they are set in spacious grounds where Nissen huts or chalets can be built. What are the basic requirements of a class of 16 postgraduates, living outside the hospital but attending all day during the week? Firstly, a common room and cloakroom should be provided, bearing in mind that there will be postgraduates of both sexes. Secondly; there must be dining room facilities where they can have lunch, and possibly tea. The hospital must provide a lecture room, suitable both for formal lectures and the demonstration of patients on staff rounds. This lecture room should be provided with blackboards, X-ray viewing boxes and slide projectors. There should be a library containing not only a selection of textbooks and journals, but also providing facilities for reading and study. A museum is of great help, and can contain not only mounted pathological specimens but also photographs and transparency viewers.

Many of these items involve expense but various sources can be tapped.

(I) Postgraduates attending the courses will pay fees. Part should go to the consultants and registrars who take part in the teaching; part can go towards improving facilities.

(2) A good deal depends on the goodwill and co-operation, primarily by the management committee but also of the regional board. It is well recognized today that a hospital which undertakes postgraduate teaching tends to be alive and progressive, and provides a better service to the 
patients and profession alike. A co-operative management committee can contribute greatly in providing facilities for postgraduates.

(3) The Nuffield Provincial Hospital Trust has decided to reserve $£ 250,000$ to finance regional and area schemes for postgraduate training in the provinces. The trustees are therefore looking forward to receiving applications from interested bodies for grants over limited periods to initiate suitable schemes. The trustees are specially concerned to see that the appropriate university and regional hospital authorities are both wholeheartedly behind any approach to the Trust, and whether there is evidence of an appreciation of the urgency, as well as of local interest and selfhelp by way of financial support.

This is a magnificent offer, and one can only hope that a similar trust can be set up for London.

The organization of a postgraduate course will vary according to local circumstances. The regional hospital can set up a teaching subcommittee of three or four interested consultants, but the actual management is best left in the hands of one consultant who can be designated by some title such as dean or director of postgraduate studies. He will require a paid secretary and preferably an office. Often it will be advisable also to appoint a registrar as postgraduate tutor, to whom postgraduates can turn for advice on day-to-day matters. A programme of ward rounds, lectures and classes will be promulgated at the beginning of each course, and certificates of attendance should be provided at the end of the course. Fees should be paid before enrolment.

Taking part in this sort of postgraduate teaching in a regional hospital for more than a decade has proved a rewarding experience. It is both pleasurable and salutary to meet doctors from many countries and to see their medical education improve and expand over the weeks of their course. Gradually the tendency to produce lists of statements, patiently gleaned from textbooks, is replaced by a more practical understanding of the problems involved and a more practical approach to management. We have had a sufficient number of unsolicited tributes from postgraduates to make us realize that these courses are helpful and that, despite our shortcomings, especially of space and facilities, the postgraduates appreciate and value the opportunity to examine patients and to take part in the life of the hospital.

Important as it is to make the best use of available facilities to overcome present difficulties, consideration of future needs must not be over- looked. The Minister has embarked on a programme of new hospital buildings and it would $\varrho$ be disastrous to miss the opportunity of providing $\frac{3}{\Phi}$ teaching facilities in some of the new larger $c$ regional hospitals. These postgraduate centres should be incorporated within the hospital and $\stackrel{\vec{F}}{?}$ should comprise:

(I) A lecture theatre suitable to seat 80 to $100 \frac{\overline{0}}{\mathrm{c}}$ people and in which patients could be $\overparen{\Phi}$ demonstrated.

(2) A smaller, more intimate room for roundtable discussions or pathology classes.

(3) A museum of pathological specimens, charts, $\vec{\omega}$ illustrations and viewing boxes for transparencies.

(4) A library and reading room.

(5) Offices for the director of studies, his secretary and a librarian.

(6) A common room and cloakroom.

(7) Dining room facilities, which could beo incorporated in the general hospital arrangements.

This teaching block would serve a much wider purpose than for the sort of postgraduate classes $\vec{\theta}$ already discussed. It would be in regular u\&ẹ for the weekly staff rounds. Improved facilities would undoubtedly lead to audiences drawn frow outside the hospital. It would be a regional centre⿳亠二口犬 for meetings of general practitioners and regional consultants, for visiting lecturers and for medical $\stackrel{\Phi}{\circ}$ conferences. It would be used for refresher $\overrightarrow{0}$ courses for general practitioners drawn from 3 various parts of the country, and it could be used for postgraduate courses for those aiming at higher degrees.

The present tendency is for the teaching hospitals to become more specialized and to devote more time, space and energy to research problems, $\frac{\delta}{3}$ to special units and to special techniques. More and more, the regional hospitals are concerned $\mathrm{O}$ with the acute emergencies and the commoner $\frac{D}{0}$ diseases requiring hospital care. Since these diseases will ultimately be the prime concern of $\mathcal{N}$ the majority of graduates, it seems likely that in $N$ the years to come regional hospitals will be called upon to play a part in the training of under- $\bar{x}$ graduates as well as postgraduates.

At present, hospitals can be adapted to some extent to meet these requirements, but in planning ${ }^{+}$ new hospitals, unless considerable foresight is ${ }^{\circ}$ used, a valuable opportunity to cater for these $\overrightarrow{\mathbb{D}}$ various needs could be lost, to the great detriment $\frac{\Omega}{\Phi}$ of the profession in the future. 